DINITROANISIDINES AND THEIR PRODUCTS OF DIAZOTISATION. 923

\title{
XCVII._Dinitroanisidines and their Products of Diazotisation (Second Communication).
}

By Raphael Meldola, F.R.S., and Frank George C. Stephens.

IN the last communication dealing with this subject (Trans., 1905, 87, 1199), two dinitroanisidines were described, and the products of diazotisation of one of these, namely, isopicramic methyl ether, studied in detail. The investigation of the other dinitroanisidine (m. p. $163^{\circ}$ ) is not yet complete, as the preparation of this compound has presented greater difficulties than were anticipated. In the meantime we have continued our experiments with the object of obtaining a dinitroanisidine corresponding to dinitro- $m$-aminophenol. As these experiments have been successful, we make known the results in the present paper.

\section{Nitration of Diacetyl-m-aminophenol.}

Neither $m$-aminophenol nor its monoacetyl derivative can be nitrated, as nitric acid gives rise to oxidation products and colouring matters with these compounds. The diacetyl derivative, first prepared by Ikuta (Amer. Chem. $J ., 1893,15,41$ ), can, however, be nitrated by the following method.

VOL. LXXXIX. 
Ordinary concentrated nitric acid (sp. gr. 1·4) cooled in ice is saturated with the crystalline diacetyl derivative by adding the latter in small portions to the extent of about one gram per two c.c. of acid. To the solution thus obtained there is then added one-half the volume of fuming nitric acid (sp. gr. 15), and, after standing for tbree hours, the solution is poured on to ice. A crystalline deposit soon separates, and after filtration the mother liquor on standing for a few days deposits a second crop. The two compounds thus obtained proved to be isomeric mononitroacetaminophenols corresponding respectively to 4-nitro-3-aminophenol (first crop) and 6-nitro-3-aminophenol (second crop).

The acetyl derivatives were purified by crystallisation from alcohol with animal charcoal and then from glacial acetic acid until the melting points were constant.

4-Nitro-3-acetaminophenol, obtained as above, crystallises in silvery scales or clusters of ochreous, prismatic needles, melting at $266^{\circ}$. It dissolves in aqueous alkali with a yellow colour.

0.0963 gave 11.7 c.c. moist nitrogen at $13^{\circ}$ and $759.4 \mathrm{~mm}$. $\mathrm{N}=14 \cdot 33$.

$$
\mathrm{C}_{8} \mathrm{H}_{8} \mathrm{O}_{4} \mathrm{~N}_{2} \text { requires } \mathrm{N}=14 \cdot 28 \text { per cent. }
$$

4-Nitro 3-aminophenol, obtained from its acetyl derivative by hydrolysis with sulphuric acid, crystallises from hot water or very dilute alcohol in slender, orange needles melting at $185-186^{\circ}$.

0.0865 gave 13.6 c.c. moist nitrogen at $17^{\circ}$ and $759.7 \mathrm{~mm}$. $\mathbf{N}=18 \cdot 21$.

$$
\mathrm{C}_{6} \mathrm{H}_{6} \mathrm{O}_{3} \mathrm{~N}_{2} \text { requires } \mathrm{N}=18 \cdot 18 \text { per cent. }
$$

The above nitroaminophenol does not appear to have been described before. Its constitution is proved by its giving $p$-nitrophenol when diazotised and boiled with absolute alcohol. The diazonium sulphate also on heating with hydriodic acid gives 4-nitro-3-iodophenol, m. p. $123^{\circ}$, which crystallises from hot water in the form of pale ochreous needles.

The methyl ether of this nitroaminophenol has been described by Bantlin (Ber., 1878, 11, 2106), who obtained it from 3:4-dinitroanisole by the action of alcoholic ammonia. We have prepared the same compound by methylating 4-nitro-3-acetaminophenol with dimethyl sulphate in presence of alkali. The methylation is very incomplete by this process, and the nitroacetanisidide undergoes partial hydrolysis by the alkali, so the product was completely hydrolysed by sulphuric acid after the removal of the phenolic (unmethylated) portion. The nitroanisidine thus obtained had the properties ascribed to it by Bantlin, only the melting point was found to be $131^{\circ}$ (Bantlin gives 
$\left.129^{\circ}\right)$. The compound was acetylated by boiling for a short time with acetic anhydride, and the product, after crystallisation from alcohol, consisted of silky-white needles melting at $124^{\circ}$.

0.0765 gave 8.6 c.c. moist nitrogen at $14^{\circ}$ and $769.9 \mathrm{~mm}$. $\mathrm{N}=13 \cdot 41$.

$$
\mathrm{C}_{9} \mathrm{H}_{10} \mathrm{O}_{4} \mathrm{~N}_{2} \text { requires } \mathrm{N}=13 \cdot 33 \text { per cent. }
$$

6-Nitro-3-acetaminophenol (second crop) is much more soluble in all solvents than the isomeride. It crystallises in pale ochreous needles melting at $221^{\circ}$ and dissolving in aqueous alkali with a yellow colour.

$$
\begin{aligned}
& \begin{array}{c}
0.0792 \\
\mathrm{~N}=14.52 .
\end{array} \text { gave } 9.7 \quad \text { c.c. moist nitrogen at } 13^{\circ} \text { and } 764 \cdot 1 \mathrm{~mm} \text {. } \\
& \mathrm{C}_{8} \mathrm{H}_{8} \mathrm{O}_{4} \mathrm{~N}_{2} \text { requires } \mathrm{N}=14.28 \text { per cent. }
\end{aligned}
$$

6-Nitro-3-aminophenol was prepared from its acetyl derivative by hydrolysis with sulphuric acid and neutralisation of the solution of the sulphate with ammonia. It crystallises from hot water in dull orange needles melting at $158^{\circ}$.

$$
\begin{aligned}
& \underset{0}{0.0964} \text { gave } 15 \text { c.c. moist nitrogen at } 19^{\circ} \text { and } 762 \mathrm{~mm} \text {. } \\
& \mathrm{N}=17.94 . \\
& \mathrm{C}_{6} \mathrm{H}_{6} \mathrm{O}_{3} \mathrm{~N}_{2} \text { requires } \mathrm{N}=18.18 \text { per cent. }
\end{aligned}
$$

This nitroaminophenol appears to be new. On diazotisation and decomposition of the diazonium salt with hydriodic acid, an iodonitrophenol was obtained, crystallising from boiling water in straw-coloured scales melting at $92-93^{\circ}$, and probably identical with the compound described by Busch (Ber., 1874, 7, 462), who gives the melting point $90-91^{\circ}$. An attempt to replace the amino-group by hydrogen by boiling the diazonium sulphate with absolute alcohol gave a product which distilled in a current of steam and which crystallised in yellow needles melting at $75^{\circ}$. This compound is phenolic, but is not, as we anticipated, $o$-nitrophenol. It is probably nitroresorcinol ethyl ether $\left(\mathrm{NO}_{2}: \mathrm{HO}: \mathrm{OC}_{2} \mathrm{H}_{5}=6: 1: 3\right)$, but this part of the subject requires further investigation.

\section{4 : 6-Dinitro-3-aminophenol and Derivatives.}

The isomeric nitroacetaminophenols above described both yield the same dinitroacetaminophenol on further nitration. The nitration is effected by dissolving the acetyl derivative in fuming nitric acid cooled to $-10^{\circ} ; 15$ c.c. of acid will nitrate about three grams of the acetyl derivative. The solution is poured on to ice and the dinitrocompound collected and washed and crystallised from alcohol or glacial 
acetic acid, from which solvents it separates in white needles melting at $168^{\circ}$.

$0 \cdot 1259$ gave 19 c.c. moist nitrogen at $15^{\circ}$ and $761 \mathrm{~mm}$. $\quad \mathrm{N}=17 \cdot 67$. $\mathrm{C}_{8} \mathrm{H}_{7} \mathrm{O}_{6} \mathrm{~N}_{3}$ requires $\mathrm{N}=17 \cdot 43$ per cent.

The above acetyl derivative is readily hydrolysed by sulphuric acid and yields $4: 6$-dinitro-3-aminophenol. The latter compound crystallises from alcohol in dull orange needles melting at $231^{\circ}$ and dissolving in aqueous alkali with an orange colour.

$0 \cdot 1139$ gave $21 \cdot 1$ c.c. moist nitrogen at $18^{\circ}$ and $757 \cdot 8 \mathrm{~mm} . \quad \mathrm{N}=21 \cdot 3$. $\mathrm{C}_{6} \mathrm{H}_{5} \mathrm{O}_{5} \mathrm{~N}_{3}$ requires $\mathrm{N}=21 \cdot 1$ per cent.

This dinitroarninophenol may be identical with that obtained by Lippmann and Fleissner by the action of an alcoholic solution of potassium cyanide on $2: 4$-dinitroaniline (Monatsh., 1886, 7, 95). These authors, however, give a lower melting point, namely, $225^{\circ}$, although in other respects the description of their compound agrees with the properties of ours. On diazotisation and boiling the diazonium salt with water, $4: 6$-dinitroresorcinol of m. p. $212-213^{\circ}$ (Typke, Ber., 1883, $16,552)$ is formed. The identity of the latter compound was established by comparison with a specimen of dinitroresorcinol prepared by the nitration of resorcinol diacetate. In order further to characterise the resorcinol derivative, it was methylated by dimethyl sulphate and alkali. Both preparations gave the same dimethyl derivative, crystallising from dilute alcohol in white needles melting at $157^{\circ}$ (Meldola and Eyre, Proc., 1901, 17, 132).* From these data, combined with the fact that the two isomeric nitroacetaminophenols both give the same product on further nitration, the constitution of the dinitroaminophenol is established :

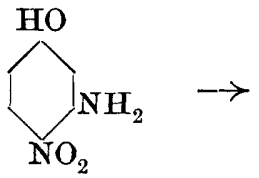

M. p. $185-186^{\circ}$.

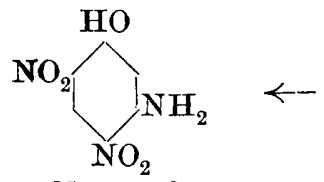

M. p. $231^{\circ}$.

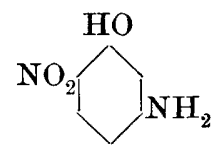

M. p. $158^{\circ}$.

* A dinitroresorcinol dimethyl ether to which the same constitution is assigned (Beilstein, II, 925) is said to have been obtained by König (Ber., 1878, 11, 1042) by the nitration of resorcinol dimethyl ether. The description of this compound by König, however, as crystallising in reddish-brown crystals melting at $67^{\circ}$ shows that his preparation was very impure. We have obtained a compound (Meldola and Eyre, loc. cit.) identical with the above by the direct nitration of resorcinol dimethyl ether in glacial acetic acid, but the product thus obtained is always mixed with colouring matters and requires much purification. The melting point given in the paper referred to is $154^{\circ}$; by repeated crystallisation we have brought it up to $157^{\circ}$. The compound is doubtless identical with that obtained by Jackson and Warren (Amer. Chem. J., 1891, 13, 164), although these authors give a melting point of $167^{\circ}$, and also by Blanksma and Terwogt (Rec. Trav. Chim., 1902, 21, 286). 
4:6-Dinitro-3-aminophenol methyl ether =4:6-Dinitro-m-anisidine. -This compound was prepared by the action of methyl iodide on the silver salt of 4:6-dinitro-3-acetaminophenol and hydrolysis of the product. The yield, however, is not very good by this method and the same compound was more conveniently prepared by the direct nitration of $m$-acetaminophenol methyl ether. In order to obtain the latter substance, $m$-aminophenol was converted into its monoacetyl derivative and the latter methylated by dimethyl sulphate in presence of alkali. The $m$-acetanisidide separates out as an oil which solidifies to a crystalline cake on standing. The crude product can, if necessary, be purified by crystallisation from very dilute alcohol, and, after purification, has the melting point $80-81^{\circ}$ assigned to it by its discoverers (Körner and Wender, Gazzetta, 1887, 17, 493).

The nitration of the $m$-acetanisidide was effected by dissolving the compound in small quantities in fuming nitric acid (sp. gr. 1.52) cooled in ice. One gram of the substance requires about 5 c.c. of acid of the strength mentioned in order to convert it into a dinitro-derivative. The product was isolated by pouring the solution on to ice, collecting and washing the precipitate, and crystallising frorn glacial acetic acid. The dinitro- $m$-acetanisidide crystallises in small, white needles melting at $146^{\circ}$.

0.0762 gave 10.8 c.c. moist nitrogen at $15^{\circ}$ and $756.8 \mathrm{~mm} . \mathrm{N}=16.5$. $\mathrm{C}_{9} \mathrm{H}_{9} \mathrm{O}_{6} \mathrm{~N}_{3}$ requires $\mathrm{N}=16.5$ per cent.

The dinitro-m-anisidine obtained from the acetyl derivative by hydrolysis with sulphuric acid or dilute sodium hydroxide crystallises from alcohol in canary-yellow needles melting at $208^{\circ}$. $^{*}$

0.0937 gave $15 \cdot 4$ c.c. moist nitrogen at $11^{\circ}$ and $768 \cdot 1 \mathrm{~mm} . \quad \mathrm{N}=19 \cdot 84$. $\mathrm{C}_{7} \mathrm{H}_{7} \mathrm{O}_{8} \mathrm{~N}_{3}$ requires $\mathrm{N}=19 \cdot 71$ per cent.

This dinitroanisidine is not diazotisable in acetic acid solution. In the presence of mineral acids, however, a diazonium salt is formed which undergoes the usual decompositions, giving rise to products which show that the reaction is in this case quite regular, neither the

* A dinitroanisidine is described in a paper by Blanksma (Rec. Trav. Chim., $1904,23,121)$ to which that author assigns the same constitution. The melting point assigned to this compound is, however, quite different, namely, $156^{\circ}$, a discrepancy which requires explanation. The evidence adduced by Blanksma in support of his formula appears to be quite sound, but we may point out that the melting point of the corresponding dinitromonomethylanisidine prepared by him $\left(198^{\circ}\right)$ is hardly in harmony with the view that it is a methyl derivative of a dinitroanisidine melting at $156^{\circ}$. The effect of the introduction of the methyl group is generally to lower the melting point. We learn from a private communication with which we have been favoured by M. Blanksma that the melting point $156^{\circ}$ is probably erroneous. 
nitro-group nor the alkyl radicle being displaced. Thus on boiling the diazonium sulphate with hydriodic acid there is formed $4: 6$-dinitro3-iodoanisole, which crystallises from alcohol in small, ochreous scales melting at $119^{\circ}$.

0.0914 gave $6 \cdot 6$ c.c. moist nitrogen at $11^{\circ}$ and $767 \cdot 9 \mathrm{~mm} . \quad \mathrm{N}=8 \cdot 71$. $\mathrm{C}_{7} \mathrm{H}_{5} \mathrm{O}_{5} \mathrm{~N}_{2} \mathrm{I}$ requires $\mathrm{N}=8.67$ per cent.

The diazonium salt (sulphate or chloride) combines at once with $\beta$-naphthol in alkaline solution to form an azo-compound which is non-phenolic, and in which the methoxy-group is therefore present. After crystallisation from boiling aniline, the compound was obtained in brick-red needles melting at $257^{\circ}$.

$0 \cdot 1073$ gave 13.6 c.c. moist nitrogen at $11^{\circ}$ and $765.3 \mathrm{~mm} . \quad \mathrm{N}=15 \cdot 24$. $\mathrm{C}_{17} \mathrm{H}_{13} \mathrm{O}_{6} \mathrm{~N}_{4}$ requires $\mathrm{N}=15 \cdot 2$ per cent.

The azo-compound dissolves in strong sulphuric acid with a violet colour, becoming redder in shade on dilution with water. The constitution of this azo-derivative and of the related compounds is show $n$ by the formulæ :<smiles>COC1CN(C)CC(=O)[N+]1=O</smiles>

M. p. $146^{\circ}$.<smiles>COC1CC(O)CN([N+](=O)[O-])C1</smiles>

M. p. $208^{\circ}$.<smiles>CO[C@H]1C[I-][N+](=O)[C@H]1[N+](=O)[O-]</smiles>

M. p. $119^{\circ}$.<smiles>COC1CN([N+](=O)[O-])CC(OC)C1[N+](=O)[O-]</smiles>

M. p. $257^{\circ}$.

The foregoing result taken in conjunction with the observations recorded in previous papers leads to the conclusion that the displacement of the nitro-group on diazotisation is not determined solely by this group being ortho or para with respect to the diazonium group, since both these conditions are fulfilled in the dinitroanisidine described in the present paper and yet no displacement occurs. The condition of displacement appears to be the proximity of another nitro-group in the ortho-position to the nitro-group, which is ortho or para with respect to the diazonium group. Other negative substituents, such as balogens, may also be capable of loosening the attachment of the displaceable nitro-group. This point will be made the subject of further investigation.

Finsbury Teghnical College. 